\title{
Exchange of greenhouse gases between soil and atmosphere: interactions of soil physical factors and biological processes
}

K A Smith

University of Edinburgh, Edinburgh, United Kingdom

Email:keith.smith@ed.ac.uk

Soil physical factors interact in complex and intimate ways with the biological processes responsible for the production and consumption in soils of greenhouse gases. In many situations the physical condition of the soil can be the major factor controlling the level of emissions. Lowering the water table by drainage generally increases the release of soil carbon as $\mathrm{CO}_{2}$, as a result of improving the supply of oxygen to aerobically respiring microorganisms - the gaseous diffusion coefficient varies by 4 orders of magnitude between well-drained conditions and saturation. This process is especially important in peats and peaty soils generally; the surface of peat soils under long-term cultivation, e.g. in the Fens and in the Netherlands and Scandinavia, has fallen by up to several metres over time. Conversely, the need for flooded, or nearflooded, conditions is an essential prerequisite for significant emission of methane, $\mathrm{CH}_{4}$. Ebullition (bubble release) and diffusion of $\mathrm{CH}_{4}$ through the aerenchyma channels in the stems and leaves of rice plants, and of natural wetland plants, are both important pathways contributing to $\mathrm{CH}_{4}$ emissions. A strong inverse relationship is often observed between the mean depth to the water table and the rate of methane emission. Aerated soils, on the other hand, are a sink for atmospheric $\mathrm{CH}_{4}$, through microbial oxidation. The main control on oxidation rate is gas diffusivity, and well-drained conditions promote the entry of atmospheric $\mathrm{CH}_{4}$ to where the methanotrophic organisms reside in the soil. The temperature response is small, because of the controlling influence of diffusion. Nitrous oxide, $\mathrm{N}_{2} \mathrm{O}$, is the third long-lived greenhouse gas produced in soils. Emission of $\mathrm{N}_{2} \mathrm{O}$ depends on the presence of mineral $\mathrm{N}$ forms (ammonium and nitrate), but is also greatly influenced by physical conditions: emissions increase markedly with increasing temperature, attributed to increases in the anaerobic volume fraction, brought about by an increased respiratory sink for $\mathrm{O}_{2}$, causing increases in the rate of microbial reduction of nitrate toN $\mathrm{N}_{2} \mathrm{O}$-- the denitrification process. Increases in soil water-filled pore space also result in increased anaerobic volume, because of the diffusion barrier provided by the water, limiting the ingress of $\mathrm{O}_{2}$; again, the outcome is often an exponential increase in $\mathrm{N}_{2} \mathrm{O}$ emission. However, when soils are nearly or completely flooded, $\mathrm{N}_{2} \mathrm{O}$ emissions decrease to low levels - the diffusion barrier presented by the water acts now to prevent the diffusive escape of $\mathrm{N}_{2} \mathrm{O}$, and it is reduced by microbial enzymes to harmless dinitrogen, $\mathrm{N}_{2}$. This phenomenon is being explored with a view to using deliberate denitrification in riparian zones to remove nitrate from field drainage water, and thus minimize water pollution, without the "pollution swapping" that would result from replacing nitrate leaching by enhanced $\mathrm{N}_{2} \mathrm{O}$ emissions. 